\title{
A comparison of the fire weather characteristics of the Melbourne dust storm (1983) and Black Saturday (2009): a high-resolution ACCESS case study
}

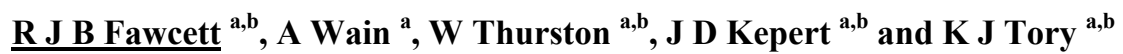 \\ ${ }^{a}$ Weather and Environmental Prediction, The Centre for Australian Weather and Climate Research \\ ${ }^{b}$ Bushfire Cooperative Research Centre \\ Email:r.fawcett@bom.gov.au
}

\begin{abstract}
We present the results of high-resolution simulations of the fire weather over Melbourne during its notorious dust storm on 8 February 1983. The simulations were performed using the Australian Community Climate and Earth-System Simulator (ACCESS), and involved a sequence of nested model runs starting with a global model run initialised with an ERA-Interim reanalysis initial condition. The ACCESS model is used at the Bureau of Meteorology for operational numerical weather prediction, but is used here in research mode at resolutions much finer than those currently used operationally.

The day of the dust storm saw the passage of a significant cool change across Victoria, with many similarities in the simulations to that of Black Saturday (7 February 2009), against which we compare it. Wind changes such as these two can have a significant (and dangerous) impact on the behaviour of bushfires in southeast Australia, and their prediction forms an important component of fire weather prediction in this part of the country. While the wind change on 8 February 1983 was accompanied by some fire activity, that activity was much less than the major fire activity which accompanied the significant wind change eight days later on Ash Wednesday (16 February 1983).

Why the dust storm wind change was not associated with severe fires, while those on Ash Wednesday and Black Saturday were, is a challenging question. Catastrophic fires are quite rare, whereas significant fire weather events that could potentially lead to catastrophic fires (if the non-meteorological prerequisites were to fall into place) are much more common and their study can lead to further understanding of the fire events.
\end{abstract}

Keywords: $\quad$ Fire weather, numerical weather prediction, Melbourne's dust storm, Ash Wednesday, Black Saturday. 
Fawcett et al., A comparison of the fire weather characteristics of the Melbourne dust storm (1983) and Black Saturday (2009)

\section{INTRODUCTION}

The notorious dust storm which blanketed Melbourne, Australia's second-largest city and the capital of the State of Victoria, on 8 February 1983 (hereafter, the dust storm day or the DSD) would never be forgotten by the millions that experienced it (BoM 2008). It came towards the end of an intense El-Niño-driven drought (Gibbs 1984, BoM 2008), which saw rainfall for the 10 months to January 1983 (Figure 1) below the 10th percentile of historical records across the entire State of Victoria, nearly $98 \%$ of the State below the 5 th percentile and nearly $60 \%$ loweston-record. In this respect, the lead up to the DSD was significantly worse than the lead up to Black Saturday (7 February 2009), with the 12 months to January 2009 having rainfall below the 10th percentile across $54 \%$ of the State.

The day of the dust storm saw the passage of a significant cool change across Victoria, with many similarities in the simulations to that of Black Saturday, against which we compare it. Melbourne reached $43.2^{\circ} \mathrm{C}$ on the $\mathrm{DSD}$, at that time a new February record and higher than the $43.0^{\circ} \mathrm{C}$ eight days later on 16 February 1983 (Ash Wednesday;

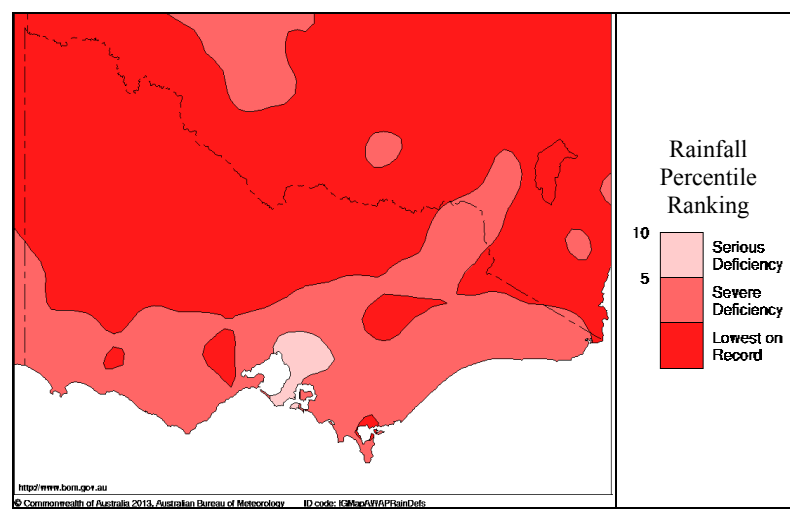

Figure 1: Rainfall percentiles for the 10 months to January 1983. The calculation is based on a distribution of monthly gridded rainfall totals (Jones et al. 2009) from April 1900 to January 2013. hereafter, AW). Figure 2 shows the contemporary mean sea-level pressure (MSLP) analysis (BoM 1983), for 0000 UTC on 8 February 1983. A cold front approaches Victoria from the west, with northerly to northwesterly winds ahead of the front, and cooler westerly to southwesterly winds behind the front. Wind changes such as this one can have a significant (and dangerous) impact on the behaviour of bushfires in southeast Australia, and their prediction forms an important component of fire weather prediction, generally. While the DSD wind change was not accompanied by significant fires, the one just a week later on AW and the one on Black Saturday were. Some fire activity on the DSD was reported in contemporary newspaper accounts, but it was evidently well below the scale of the AW fires. This leads us to ask the following question: to what extent is the difference in the fire outcomes attributable to the meteorology and antecedent climatic conditions?

\section{MODELLING}

This paper describes high-resolution and veryhigh-resolution numerical weather prediction (NWP) modelling of the two cases, using the Australian Community Climate and Earth-System Simulator (ACCESS) and in particular the United Kingdom Meteorological Office's atmospheric model which comprises the atmospheric component of ACCESS. The modelling of the Black Saturday case uses a configuration similar to that used by Engel et al. (2013), and accordingly gives

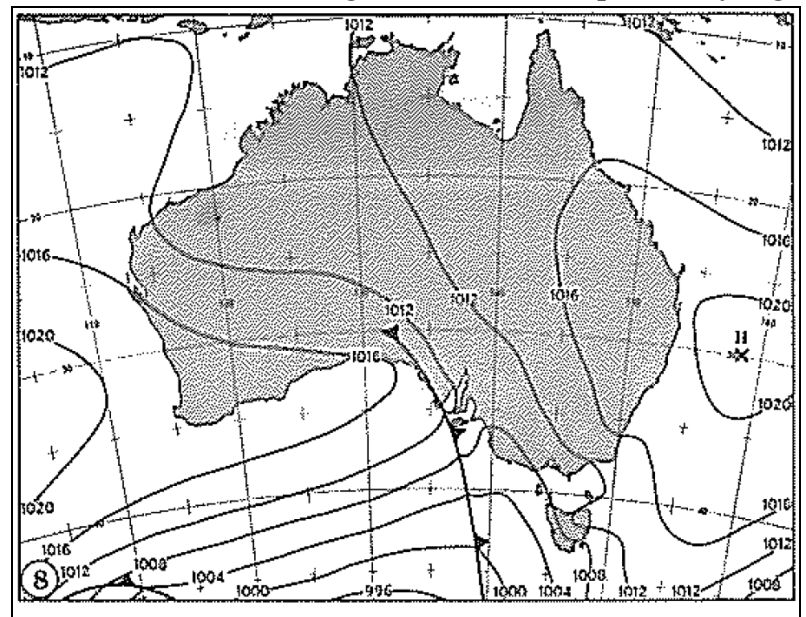

Figure 2: Contemporary MSLP analysis for 0000 UTC 8 February 1983, obtained from BoM (1983). Pressures are in $\mathrm{hPa}$. The approaching cold front is indicated by the thick black line with triangles.

similar results. In order to simulate the weather conditions on the two days, a sequence of nested model runs is employed, starting with a global model run and progressively nesting down to a region of approximately $900 \mathrm{~km} \times 650 \mathrm{~km}$. In total, there are five levels to the nesting process. The second-level domain $\left(0.11^{\circ}\right.$ grid spacing) extends well to the west of Australia, while maintaining a $20^{\circ}$ buffer to the south, $35^{\circ}$ to the east and $35^{\circ}$ to the north. The third level $\left(0.036^{\circ}\right.$ grid spacing $)$ covers Victoria, Tasmania and southern New South Wales, while the fourth level $\left(0.012^{\circ}\right.$ grid spacing) covers Victoria and southern New South Wales (Figure 3). [A fifth-level $0.004^{\circ}$-grid-spacing simulation across central Victoria was performed for the Black Saturday case study, but its results have not been used in this paper, as the DSD simulations were only done down to the $0.012^{\circ}$ grid spacing (which is approximately $1.3 \mathrm{~km} \times 1.1 \mathrm{~km}$ ).] Domain boundaries have been placed, where possible, to avoid regions of significant topography. All five levels of nesting use 50 vertical levels, 
Fawcett et al., A comparison of the fire weather characteristics of the Melbourne dust storm (1983) and Black Saturday (2009)

with the lowest model level being approximately 10 metres above the surface for some variables (e.g., the $u$ and $v$ components of the horizontal wind) and approximately 20 metres above the surface for other variables (e.g., potential temperature $\theta$, vertical wind velocity $w$ ). For more details on the nesting process, see Fawcett et al. (2013a,b).

The Black Saturday simulations use a global initial condition obtained from the UK Met Office valid at 2009-02-06 $0300 \mathrm{UTC}$, while those for the DSD use an ERA-Interim reanalysis valid at 1983-02-07 0000 UTC, but in other respects the modelling frameworks are identical. Thus in each case, the relevant portions of the meteorology are around 24 to 36 hours into the integration. The hindcasts are prepared as initial-value problems, with no meteorological information subsequent to the initial condition being assimilated into the hindcasts.

\section{MODEL VALIDATION}

For simulations of recent events (e.g., Black Saturday), the model results can be validated against

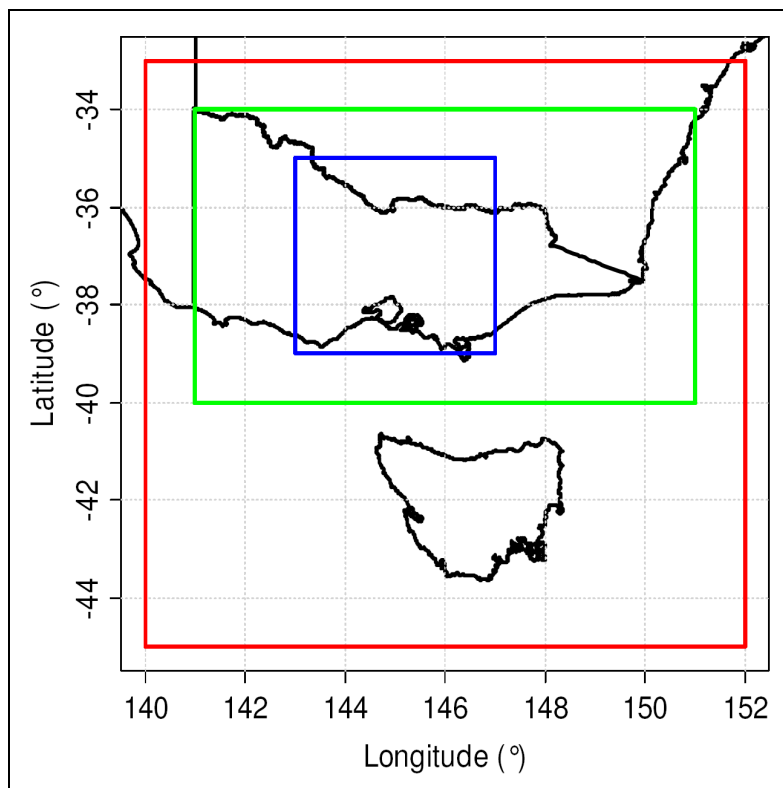

Figure 3: Model domains for the $0.036^{\circ}$-grid-spacing (red), $0.012^{\circ}$-grid-spacing (green) and $0.004^{\circ}$-gridspacing (blue) simulations of the Black Saturday meteorology. automatic weather station (AWS) data, balloon-flight data, radar data and satellite data, all available in digitised form. The simulations of 2-metre air temperature and 10-metre horizontal wind direction are quite satisfactory in the Black Saturday simulations, with 10-metre horizontal wind speed being somewhat underestimated: this is a common failing of current NWP systems. The timing of the primary wind change within the ACCESS simulations has an accuracy of within one hour, around 24 hours into the integration, something rather better than what was operationally achievable at the time in 2009. More details on the validation of this simulation can be found in Fawcett et al. (2013a).

For simulations of more remote events (e.g., the DSD), the available data are much fewer, and validation of the simulations accordingly much harder. Still, there are two AWSs available; Melbourne and Sydney Airports. Results for Melbourne Airport are shown in Figure 4. The primary wind change is about two hours late at Melbourne Airport in the $0.012^{\circ}$ grid-spacing simulation, although only about 80 minutes

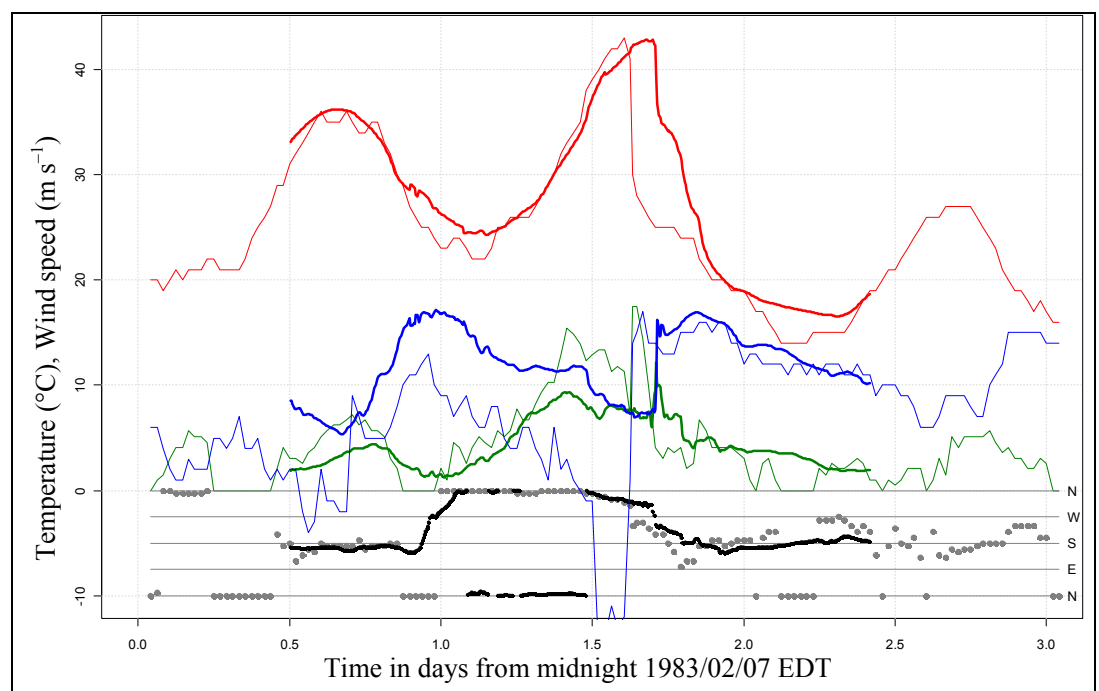

Figure 4: Comparison of AWS observational (thin lines, grey dots) and model (thick lines, black dots) data for Melbourne Airport. 2-metre air (in ${ }^{\circ} \mathrm{C}$, red lines), and dewpoint (in ${ }^{\circ} \mathrm{C}$, blue lines) temperature and 10-metre wind speed (in $\mathrm{m} \mathrm{s}^{-1}$, green lines) are shown, together with wind direction (dots). Model data are from the $0.012^{\circ}$-grid-spacing simulation, using the grid point nearest the location of the AWS. Times are in Eastern Daylight Time (EDT $=$ UTC +11 hours). late in a parallel simulation initialised 12 hours later (at 1200 UTC on 1983-02-07). The morning minimum temperature and the afternoon maximum temperature are well simulated, as is the pre-change (northerly to northwesterly) wind direc- 
Fawcett et al., A comparison of the fire weather characteristics of the Melbourne dust storm (1983) and Black Saturday (2009)

tion. Peak wind speeds ahead of the change are underestimated, as are pre-change dewpoint temperatures, although post-change dewpoint temperatures are well hindcast.

\section{RESULTS}

Figure 5 shows the 10-metre wind-direction field in the $0.012^{\circ}$-grid-spacing simulations at the time at which the simulated primary wind change (PWC) crosses the Melbourne CBD. Those times are around 0650 UTC (1750 EDT) in the Black Saturday simulation and around 0600 UTC (1700 EDT) in the DSD simulation. The Black Saturday PWC has a northwest-to-southeast orientation. Although not a straight line, it is somewhat parallel to the western half of the New South WalesVictoria border, which it has not yet reached at that time. It has, however, passed through Wilsons Promontory east of Melbourne. In contrast, the DSD PWC is noticeably more meridional, having reached the border in the northwest but not having passed through Wilsons Promontory.

In spite of this difference in the orientation, there are many similarities in the simulations. They both show secondary wind changes trailing behind the PWC, associated with the differently oriented sections of the Victorian coastline west of Port Phillip (see Fawcett et al. 2013a for an extended discussion on this in relation to the Black Saturday simulations). The segments of the PWC east of Melbourne in Figure 5 both show a convex shape. The segments of the PWC west of Melbourne both show areas where the southwesterly flow (yellow shades) behind the PWC revert to a more westerly to northwesterly flow (orange shades). Ahead of the PWC, they both show indications of pronounced wind-direction variability: in the Black Saturday case, there is strong confirmatory observational evidence of prefrontal boundary-layer rolls breaking up into more cellular convection as

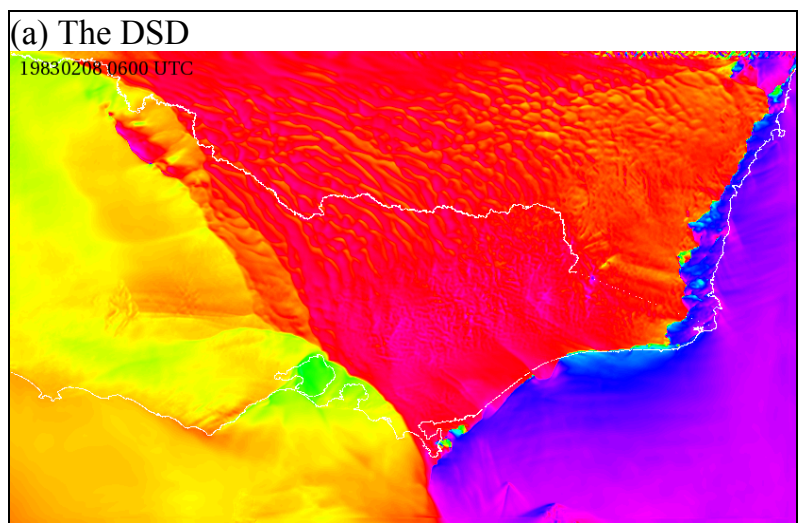

(b) Black Saturday

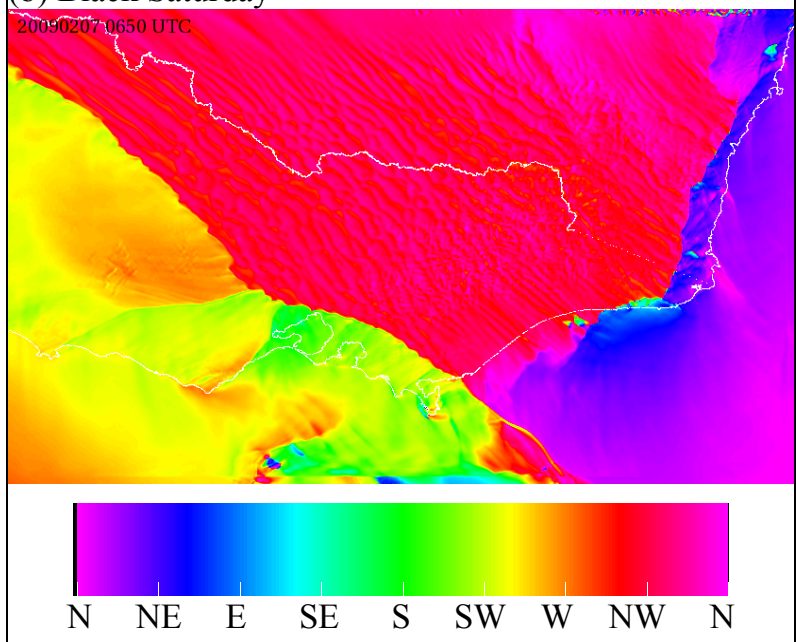

Figure 5: Wind direction at the time the primary wind change in the model passes through the Melbourne $\mathrm{CBD}$ in the $0.012^{\circ}$-grid-spacing simulation, for (a) the DSD (0600 UTC) and (b) Black Saturday (0650 UTC). the day heats up (Engel et al. 2013). In the evening, both simulations show the PWC stalling, and an undular bore forming in the emerging stable nocturnal boundary layer and detaching from the PWC (not shown).

\section{DISCUSSION AND CONCLUSIONS}

Observational evidence indicates that the dust in the dust storm on 8 February 1983 was contained within the density current of the cold front, up to heights of some hundreds of metres above ground level. For example, Gibbs (1984) reports that the dust cloud had a north-south alignment as it approached the Melbourne CBD. This suggests that the dust arrived at Melbourne in the post-frontal (cooler westerly) air stream, rather than in the pre-frontal (hot northwesterly) air stream. In order for the dust to be brought up towards the leading edge of the front and then distributed laterally along the front, it would be necessary for the horizontal wind speeds immediately behind the front to be greater than the actual propagation speed of the front. This is seen in the $0.012^{\circ}$-grid-spacing simulation as the modelled cold front proceeds up the western coast of Port Phillip towards Melbourne: the horizontal wind speeds in the third model level (130 metres above the model ground level) are indeed greater than the front propagation speed (not shown).

Black Saturday and AW were days of very significant bushfires in southeast Australia, while the DSD was not. The issue of human-caused ignition, deliberate or inadvertent, direct or indirect, is necessarily beyond the scope of this study, and since human-caused ignition is reported to have been a factor in at least some of the Black Saturday fires (VBRC 2010), a complete explanation of the differences in outcomes between the DSD and Black Saturday cannot rest on the meteorology and antecedent climatic conditions alone. As noted 
Fawcett et al., A comparison of the fire weather characteristics of the Melbourne dust storm (1983) and Black Saturday (2009)

above, there were fires present on the DSD, but these were not on the scale of those on AW and Black Saturday.

Black Saturday was markedly hotter: the maximum temperature averaged across Victoria was $44.5^{\circ} \mathrm{C}$ on Black Saturday, compared with $40.7{ }^{\circ} \mathrm{C}$ on the DSD and $41.1^{\circ} \mathrm{C}$ on AW (calculations based on the daily maximum temperature analyses of Jones et al. 2009). In terms of the FFDI (Mark 5) calculation of Noble et al. (1980), the temperature difference would have resulted in FFDI values being around 14\% higher on Black Saturday than on the DSD, other things (relative humidity, wind speed, drought factor) being equal (although the difference in this respect between AW and the DSD would have likely been negligible). The three days were similar in terms of antecedent rainfall: there was negligible rainfall over central and western Victoria in the two weeks prior to the events. [There were some differences in the far east of the State, but that is not likely to have been a relevant factor. In terms of the week prior, the Victorian State-averaged rainfall for the seven days to 9 am on the DSD was a meagre 0.4 $\mathrm{mm}$, compared with $1.5 \mathrm{~mm}$ for AW, but in both cases what rain fell in the State was again largely confined to the far east (calculations based on the analyses of Jones et al. 2009).]

Figure 6 shows the times in the two $0.012^{\circ}$-gridspacing simulations when the notional instantaneous FFDI is broadly at its peak over western Victoria. For the DSD, simulated FFDI values reach the 75 to 100 ("Extreme") range over broad areas of western Victoria, but on Black Saturday broad areas are in the 100 to $125(>100$ is "Catastrophic") range, and near the coast approach 160 . [Even higher values are seen in the $0.004^{\circ}$-gridspacing simulation for Black Saturday because of its ability to simulate locally higher wind speeds.] In the DSD simulation, "Catastrophic" FFDI values are modelled over very small areas, apparently associated with convective downdrafts, but in general terms the Black Saturday FFDI values are significantly higher than the DSD values.

Peak wind speeds at Melbourne Airport were a few metres per second higher on Black Saturday than they were on the DSD (not shown), although it should be noted that there are data every minute for Black Saturday but only every 30 minutes for the DSD, so the apparent difference might arise at least in part from data availability. Hence we con-

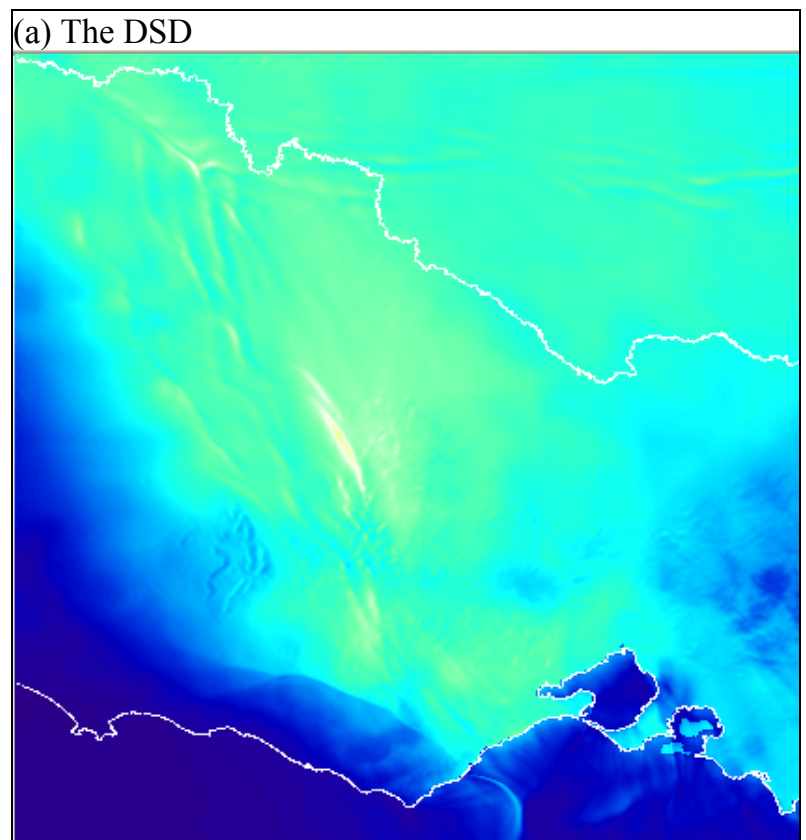

(b) Black Saturday

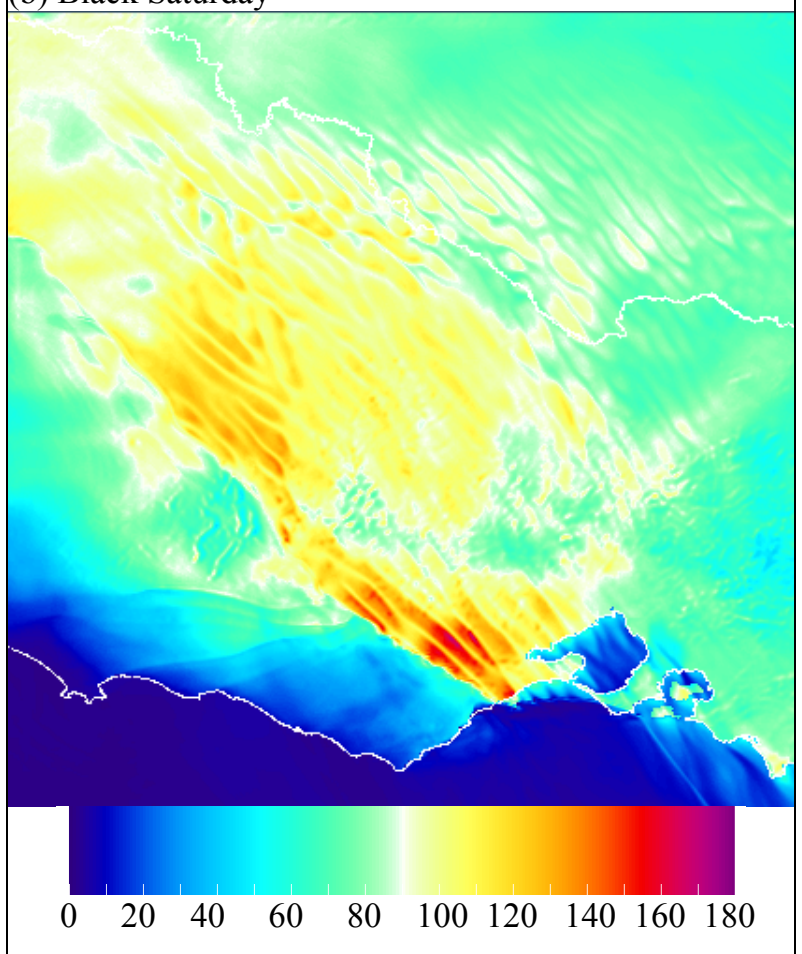

Figure 6: Notional instantaneous FFDI values over western Victoria for (a) 0340 UTC the DSD and (b) 0430 UTC on Black Saturday. A drought factor of +10 is assumed. The drought factor is a non-dimensional index of fuel dryness, ranging from 0 for very moist conditions up to 10 for very dry conditions.

clude that the higher FFDI values on Black Saturday are arising from both higher temperatures and stronger winds, although with more confidence in the former than in the latter.

The question posed at the beginning of this paper was "why did Black Saturday yield catastrophic fires, but the DSD did not?" Weather conditions on the DSD were clearly bad enough to support significant bushfires, with FFDI values reaching the "Extreme" range, although those on Black Saturday were markedly higher. 
Fawcett et al., A comparison of the fire weather characteristics of the Melbourne dust storm (1983) and Black Saturday (2009)

The fuel load on Black Saturday was evidently sufficient to support catastrophic fires. The fact that catastrophic fires were seen on AW, only eight days after the DSD, leads to the very reasonable conclusion that those fuel loads were also present eight days earlier on the DSD. The antecedent rainfall conditions were comparable, as reported above, and estimated drought factor indices were very high on both days. The DSD cold front itself brought little rain; zero rainfall totals for the 24 hours to 9 am on 9 February were widespread in Victoria, and the State-averaged total for the day was less than $0.05 \mathrm{~mm}$. The State-averaged drought factor, calculated from the analyses of Dowdy et al. (2009), for the DSD was 9.70, only marginally below the AW value of 9.78. This suggests that the fuel dryness on the DSD would have been almost as high as it was eight days later. Hence we may conclude that the fuel load and dryness on the DSD were capable of supporting significant and perhaps even catastrophic fires.

That ignition sources were available on Black Saturday (VBRC 2010), is necessarily true in light of the disastrous outcomes of that day. The same obviously may be said of AW. Were there ignition sources on the DSD? Contemporary newspaper reports list numerous small fires (e.g., at Mount Evelyn and near Morwell), but not in the scale of AW. Similarly, there were fires during the heatwave at the end of January 2009 that preceded Black Saturday. In conclusion, it seems likely therefore that the difference in the fire outcomes between the DSD on one hand and AW and Black Saturday on the other largely lies outside the meteorology and antecedent climate conditions.

\section{REFERENCES}

Bureau of Meteorology 1983. Monthly Weather Review Victoria February 1983. Bureau of Meteorology, Melbourne.

Bureau of Meteorology 2008. Climate of Australia. Bureau of Meteorology, Melbourne. 214pp.

Dowdy A J, Mills G A, Finkele K and de Groot W 2009. Australian fire weather as represented by the McArthur Forest Fire Danger Index and the Canadian Forest Fire Weather Index. CAWCR Technical Report No. 10. Centre for Australian Weather and Climate Research, Melbourne, Australia.

Engel C B, Lane T P, Reeder M J and Rezny M 2013. The meteorology of Black Saturday. Quarterly Journal of the Royal Meteorological Society 139 585-599. DOI: 10.1002/qj.1986.

Fawcett R J B, Thurston W, Kepert J D and Tory K J 2013a. The meteorology of Black Saturday: a highresolution ACCESS modelling study. CAWCR Technical Report (in review).

Fawcett R J B, Thurston W, Kepert J D and Tory K J 2013b. Modelling the fire weather of Black Saturday. In Proceedings of Bushfire CRC \& AFAC 2012 Conference Research Forum, 28 August 2012, Perth (ed. R P Thornton and L J Wright) pp135-149.

Gibbs W J 1984. The Great Australian Drought: 1982-1983. Disasters 8(2) 89-104.

Jones D A, Wang W and Fawcett R 2009. High-quality spatial climate data-sets for Australia. Australian Meteorological and Oceanographic Journal 58 233-248.

Noble I R, Bary G A V and Gill A M 1980. McArthur's fire-danger meters expressed as equations. Australian Journal of Ecology 5 201-203.

Victorian Bushfires Royal Commission 2010. 2009 Victorian Bushfires Royal Commission Final Report. The State of Victoria. Government Printer for the State of Victoria, Melbourne, Australia. 